\title{
ARTWORK DISPLAY IN UILS MERUYA
}

\author{
Ariani Wardhani \\ Universitas Mercu Buana Jakarta, Indonesia
}

\begin{abstract}
Display is a channel for any artist to stay exist and sell their artwork in an exhibition. The display itself might be considered as a link and a bridge to multiple aspects and elements that are present in the exhibition room under certain intention and objective. Departing from the statement, the team of Community Service would like to educate and display the artworks of the people with disabilities in the Unit of Community Service Meruya through a training program in order to draw the purchase interest of the surrounding community toward their artworks. In brief, exhibition might be considered as a form of business meeting between the producers and the customers. In a more specific manner, exhibition might be considered as a promotional activity that has been performed by producers, groups, organizations or certain associations in the form of product display for the relation or purchase candidate. Through the training program and the experience of designing interesting display, it is expected that the artworks of the people with disabilities might gain high sale value and might be useful for their life.
\end{abstract}

Keyword : Display, Exhibition, Design, Promotion

\section{INTRODUCTION}

In the daily life, art presents in the middle of the individuals not as a tool for serving the needs toward aesthetics but instead as a tool that accomodates a number of other needs in relation to the psychological, social and cultural problems. As part of a discipline, art has theory, concept, method and technique that might be applied in order to provide alternative solutions (Rohidi, 2001). In relation to the statement, artwork display might be a very fundamental basis for the management of art exhibition or other activities. The introduction of or the understanding toward display is a key of success within an art exhibition.

According to Ferguson, exhibition is the "medium" of an art that communicates the strategic system of representation. In addition, exhibition might also serve as an effort for pursuing the conversation with the audience and the inter-audience conversation that has been aranged in order to define the values and even the social relationship (Susanto, 2011: 289). In other words, exhibition does not oly serve as a vessel for artists to stay exist but also as a bridge to numerous aspects and elements within the display room of an exhibition under certain intention and objective.

The objective of an exhibition is to serve as an appreciation to the artists. Display has the sense of show or performance, which might refer to the system of certain object arrangment. If the term display is added by either prefix or suffix, then the term display might refer to the system of arrangment wihtin a display room. In general, the process of exhibition management cannot be set apart from the model of management, especially in the process of business management that consists of planning, organizing, motivating and controlling.

The needs toward the design stand in an exhibition is inevitably significant especially for the large-scale exhibition. With the presence of exhibition stand, the promotion of trading product or service will be facilitated.

Usually, the display stand relies on the electric lamp and other power sources for the decoration. The more interesting a stand is, the more possible will be that the customers will come to the stand. Therefore, the design stand should be designed in such a way that the stand will be able to draw the interest of the potential customers. In order to do so, the display stand should be uniquely created by following the theme of the exhibition.

\section{THEORETICAL REVIEW}

Exhibition is a form of business meeting between the producers and the buyers. In a further sense, exhibition might be defined as a promotion activity done by producers, groups, organization or certain associations in the form of product display before the relation or the customer candidates. Departing from the definition, exhibition might be classified into several categories as follows: show, expo,fair or bazaar. Within an exhibition, a display stand refers to the place or the room inside the exhibition site that has been designed by using partitions and other interiors such as chairs, tables and alike for displaying the artworks or the products. 


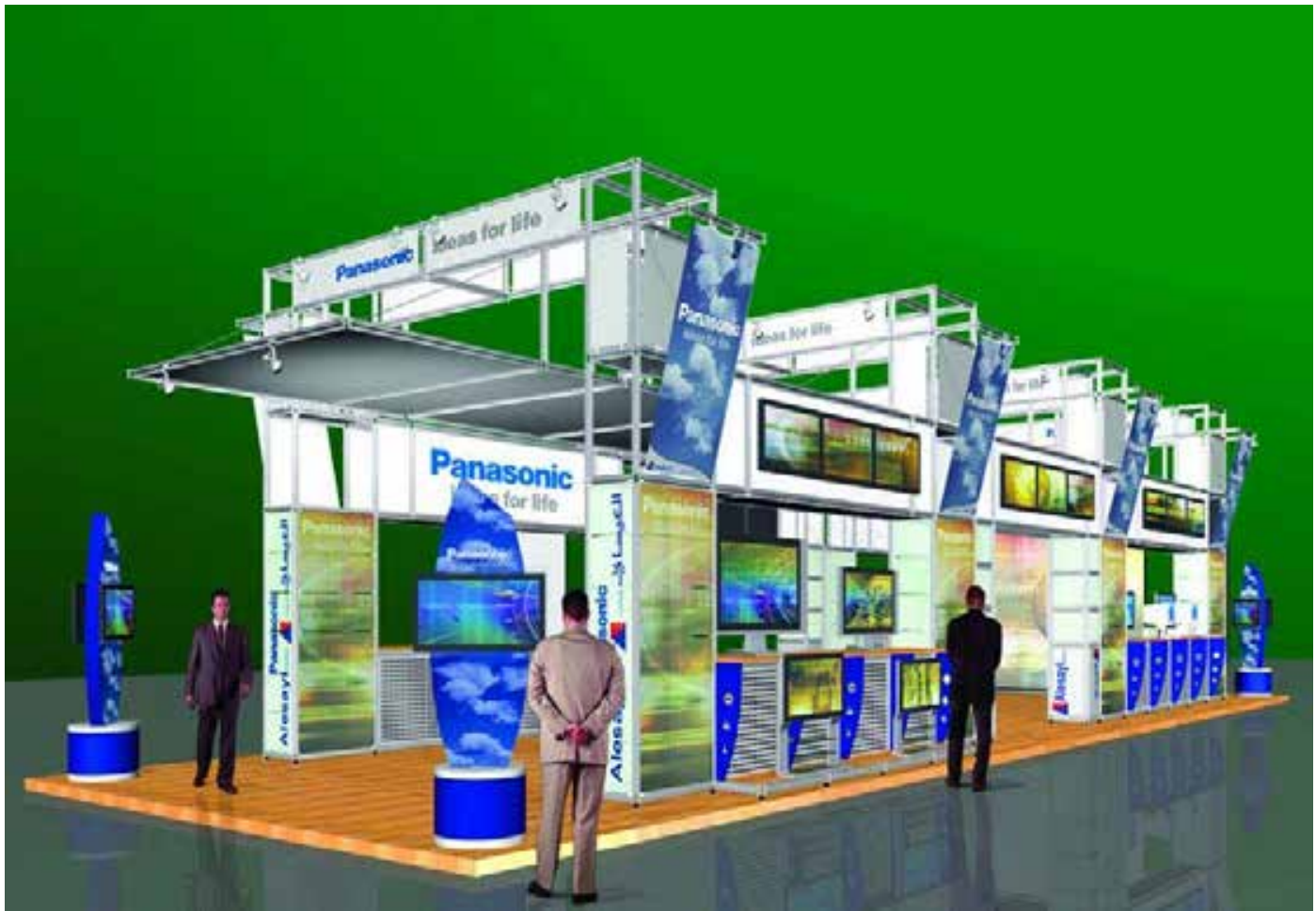

Figure 1. Example of display stand

Source : http://www.duniacyber.com/images/iklan/jasa/tono/2008-01-16/Panasonic[1].jpg

With regards to display stand, there are several tips about how create small yet powerful booth and these tips might also be applied to the graphic desighn or the display design. The 8 tips might be consulted through the following elaboration:

\section{Use Lamp}

Almost all convention centers have good lighting inside the building. As a result, an exhibition participant might anticipate the small-scale lighting on the small booth without having to add the number of the lamp due to the limited fund. However, it will be wiser for an exhibition participant to spend extra fund by installing additional spotlights on the ceilling of the convention centers. By doing so, the exhibition participant might save a little fund without having to consider the construction of the lamp hanger. Based on the results of a research in the exhibition industry, good and interesting lighting might improve the awareness to an exhibition for approximately $30 \%$ to $50 \%$. Therefore, the presence of good and interesting lighting is highly significant for an exhibition.

2. Apply "Novel" Approach

In order to be interesting, an exhibition participant should develop a specific theme for his or her booth (display design). The only way to do that is to leave behind the traditional approach and to let the booth to belong to the visitors in an area with huge coverage so that the booth might be standing out.

3. Use Appropriate Product Display

An exhibition participant should afford displaying the product and the company brand in an eye-catching angle (this might refer to the interior design of the display booth).

\section{Keep Being Simple and Uncluttered}

For the sake of economicality, an exhibition participant may only display one or two products in the booth.

\section{Size Everything to Fit the Booth}

This tip is related the interior design of a booth. For example, if an exhibition participant only wants to the sell the rims of a car then he or she does not need to display the whole car. In other words, an exhibition participant might use effective design in a booth by involving smaller items such as multimedia monitor (TV or Plasma TV) and posters or graphics. To gain a stronger event, it is prohibited to use the big counter table that might have been used in the previous exhibition.

\section{Use Visual Media with Strong Influence}

To make a display booth interesting, the design architecture of the display booth might be equipped with bigsized posters. However, the posters should not be filled with big-sized pictures or images. Instead,the posters should be added by the relevant copy of texts or words in accordance to the proportion of the posters for the sake of economicality and readability.

\section{Put Graphics on the Eye Level of the Visitors}


The ideal bottom line of a graphic is $90 \mathrm{~cm}$. If the bottom line is lower than $90 \mathrm{~cm}$, then it will be possible that the graphic will be obstructed by the product display.

\section{Use Interesting Combination of Colour}

The interesting combination of colour is important to be applied onto a booth so that the booth wil be eye catching and standing out in the crowded exhibition area. One thing that should be given attention is that the neutral colour (on the booth design) will be "faded" in the middle of the crowded exhibition area.

\section{PREPARATION OF DISPLAY STAND}

The tools and equipment should be prepared appropriately in designing the display stand and the display partition of a large-scale exhibition since there will be many companies under the similar lines that might take participation in the exhibition. To achieve this end, an exhibition participant should not imagine first the layout of the booth but instead an exhibition participant should define the objective that should be achieved from the participation in the exhibition. In relation to the statement, the objective that might be achieved from the participation in a large-scale exhibition is as follows:

1. Sale

2. New product promotion

3. Customer service

4. Large-scale project identification

5. Big sale activities

In a large-scale exhibition where the participants pursue high sale figure, the above objectives are not incorrect. However, there should be alternative objectives in designing the display booth so that the display booth will be interesting for the visitors. As an illustration, a stand should have different atmosphere or otherwise the visitors will not be entertained. In order to make a stand more interesting, several items below might be added:

1. Customer Service table

2. Display of company portfolio

3. Guest Room, that might serve as a place for Talkshow or Product Presentation

4. Rack for discount products / big sale activities

5. Standing banner

Every element or layout in the display booth should be able to visualize the preliminary objective that has been pursued.

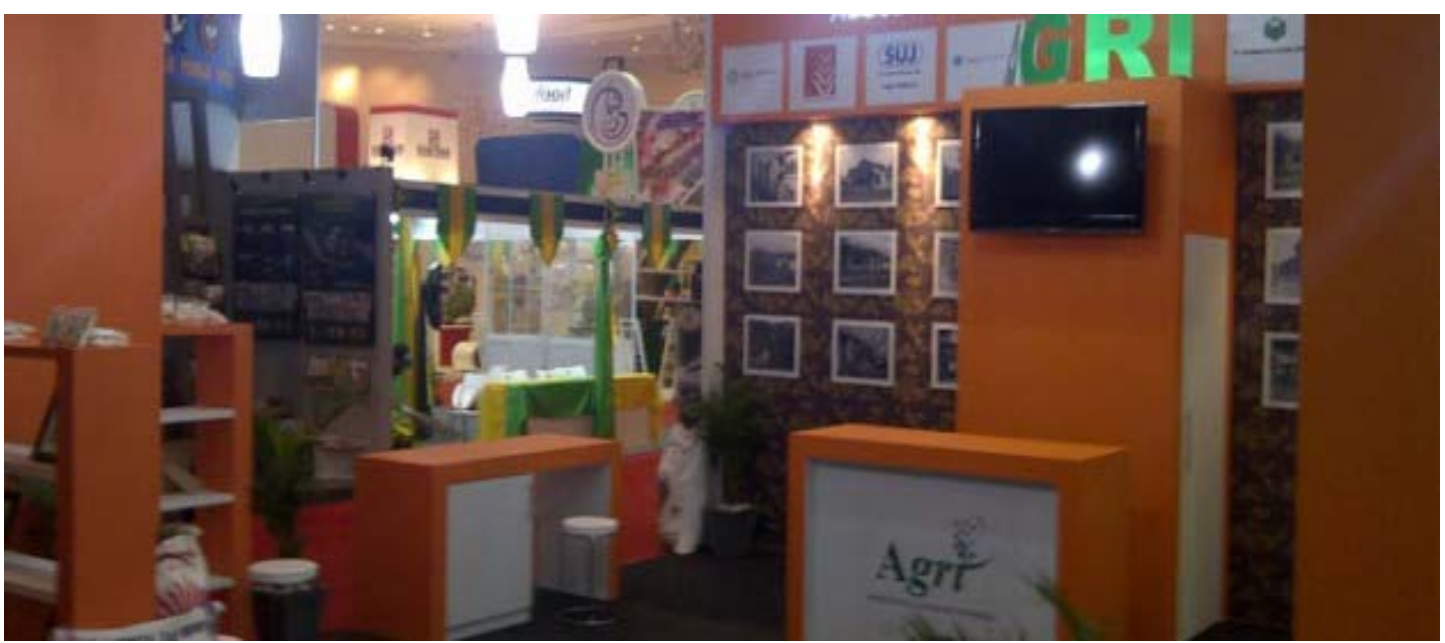

Figure 2. Example of Display Booth

Source : http://arsindociptakarya.com/wp-content/uploads/2012/07/

In the middle of 1980s, Max Kisman, one of the leading graphic designers in Netherland, pioneered the digital technology of graphic design for the magazine "Language Technology" and the pster for the Paradiso Concert Hall in Amsterdam. Kisman was born on 1953, completed his degree in the major of Graphic and Illustration Design from the Academy for Art and Industry in Enschede, Netherland, and from the Gerrit Rietveld Academy, Amsterdam (1972 - 1977). Then, after his graduation, Kisman started to design exhibitions, books, magazines, calendars, animations, posters, stamps and fonts. In 1986, he established Typografisch Papier (TYP), an alternative magazine about typography and art. Next, in 1989 - 1992 he worked and stayed in Barcelona. Within this period, he used to design the fonts for the FontShop International in Berlin, German, and also for the Fuse. Since 1992, he had been concentrating on the televion. He created the graphic design and the 
animation for the VPRO TV Station, a progressive TV Station in Netherland. Afterward, he mostly worked on the graphic design for the digital and interactive media. Nowadays, he has been teaching Graphic Design.

As a designer, Kisman highly prioritizes originality, characters, experiment, integrity, courage, clarity, emotion and personality. In creating his artworks, Kisman breaks down the complicated information into their simplest form, look for the core of the information and even sometimes reaches abstraction. Simplicity is the most explicit matter in imagery, typography and design. For Kisman, achieving simplicity and balance in graphic design is the main menu. He once said, "Balance is a dance to share together, the rhythm and grace with beauty, in motion, passion and dialogue, one step after the other." In relation to this elaboration, graphic design has been a popular topic and artwork in Yogyakarta. Graphic design in this regard refers to the combination of the creative works between human and technology. In many domains, graphic design has been playing numerous roles and functions. Therefore, it is no wonder that graphic design has been one of the creative industry chains in Indonesia. Looking at the potentials, Yogyakarta has opened widely the sites for learning about the graphic design and through the Display of Graphic Design Works it is expected that the insight about graphic design topics might be enriched in Yogyakarta.

Furthermore, learning from several booths within certain exhibitions, it might be concluded that the design of these booths is quite a bit forced. The situation is apparent from the display of abundant number of products within a limited space. Indeed, such display manner provides a sense of security since the visitors will be able to see the products that have been created and thus might draw more and more potential buyers. In other words, it might be possible there will be higher sale figure. However, it is still a possibility because the visitors have to spend extra effort in picking up the best products from the display. As a result, instead of increasing the sale figure, such display manner might be decreasing the sale figure. With the abundant number of visitors, the booth that has been designed should be outstanding in comparison to the booth of the competitors. In order to achieve this end, an exhibition participant should look for the theme that might support the items ion sale. In this case, an exhibition participant should design a booth with contrast background so that the display might be well supported.

\section{IMPLEMENTATION METHOD}

The training program of Display Media Creation had been well understood by the administrators and the members of UILS Meruya so that the training sequence might be performed smoothly. With the sufficient understanding, the following objective might be expected to be achieved:

1. Serving as aid provider instead of instruction provider

2. Providing understanding and interpretation about interesting visual media for creating display together

3. Performing the training program directly and carefully

4. Performing the training program enthusiastically and openly under direct meeting between the instructor and the participants

5. Being centred on the needs of the users within the display media creation so that the administrators and the members of UILS Meruya might learn interesting visual media and sale their artworks through the interesting visual media in the future.

The training program, that consisted of two sessions and lasted in one day only, ran well and perfectly. In the first session, the instructors explained about interesting visual media to the participants. The participants were invited to observe the interesting exhibitions so that they gained good references. In the same time, through the observation toward the exhibitions the instructor would like to pursue the participants' enthusiasm in learning something new. Then, in the second session, the instructors trained the participants by using the already available tools and materials. The paper-based materials were glued together with the cardboard according to the design elements that had been explained in the first session.

During the explanation about design theory in terms of shape, colour and layout, the participants were enthusiastic and many of them asked about the shape and the figures in the theory. They had been unable to imagine how to apply these figures into the materials that had been prepared. Then, moving to the second session, the participants became more enthusiastic as they directly practiced the application of the figures and the colour papers into the creation of interesting visual media. At the introduction of the second session, the instructors provided overall explanation on the use of the figures, the materials and the tools. Then, the participants are provided with the opportunity to directly apply their knowledge into practice. After the participants learned about the figures, the materials and the tools, along with the available software, they started to work on their own assignments. Many participants asked about the use of the figures because they had not been operating the tools and cutting the colour papers. However, since design had been an interesting activity to do, the second session turned out to be the most interesting session. Apart from the design activities, the training participants asked and helped one another since they had been assigned into groups.

The results of the Community Service Program seemed to have good acceptance from the participants. Specifically, the results of the second session was in the form of media display for UILS Meruya. With regards to the media display, the training participants were divided into four groups and each group was assigned to 
create interesting birthday card. Each group consisted of five people and every person in the group held his or her own job description and yet they still helped one another in order to create an interesting birthday card.

The design of the birthday card was a pop-up one. Consequently, the pictures or the ornaments in the birthday card should be embossed. Then, the method for creating the pop-up birthday card was an experimental one with the following tools and materials:

1. Scissors

2. Paper glue

3. Pencil and ruler

4. Decoration

5. Cutter

6. Double tape

Figure 3. Tools and materials
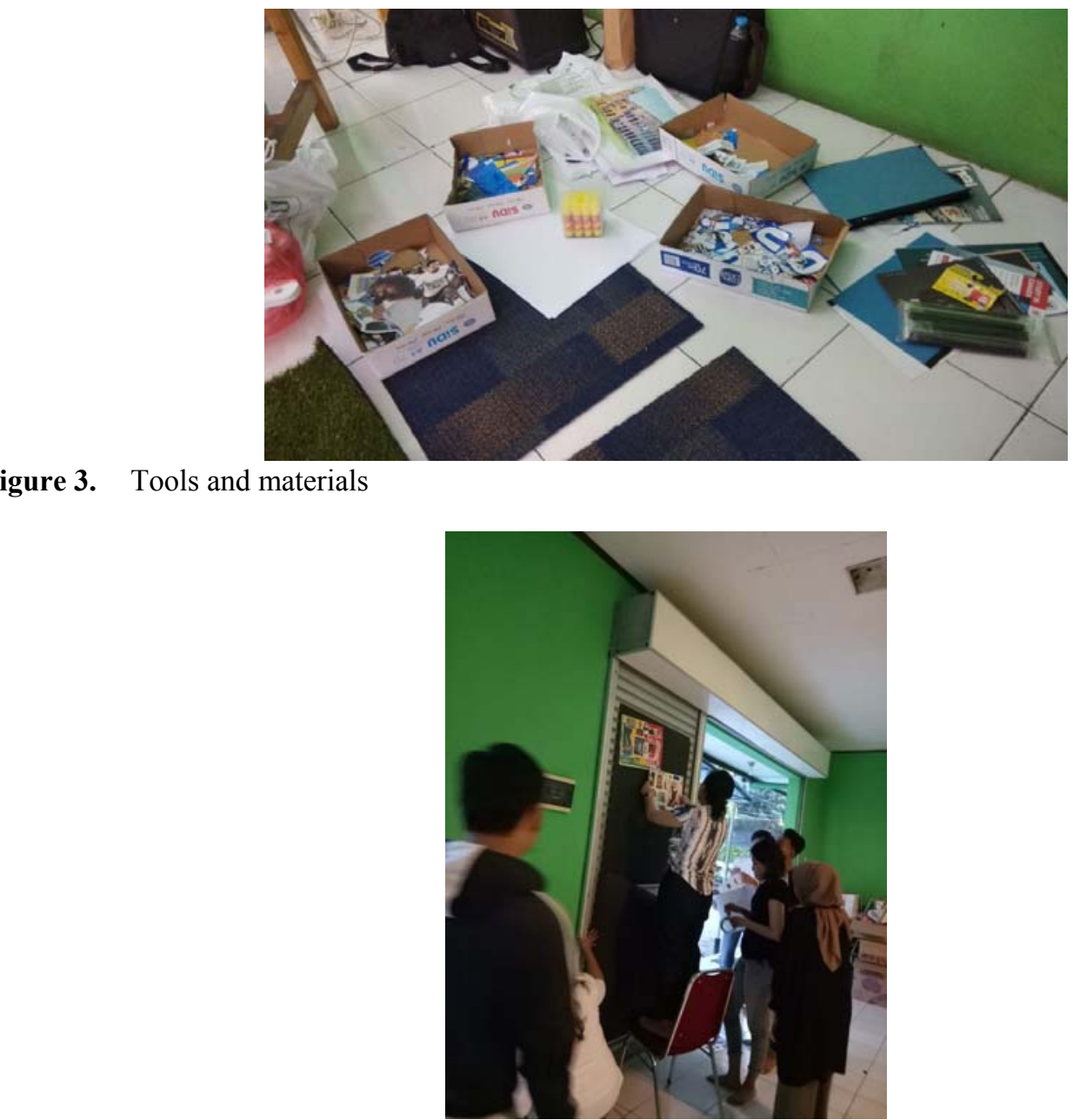

Figure 4. Display exhibition in UILS Meruya

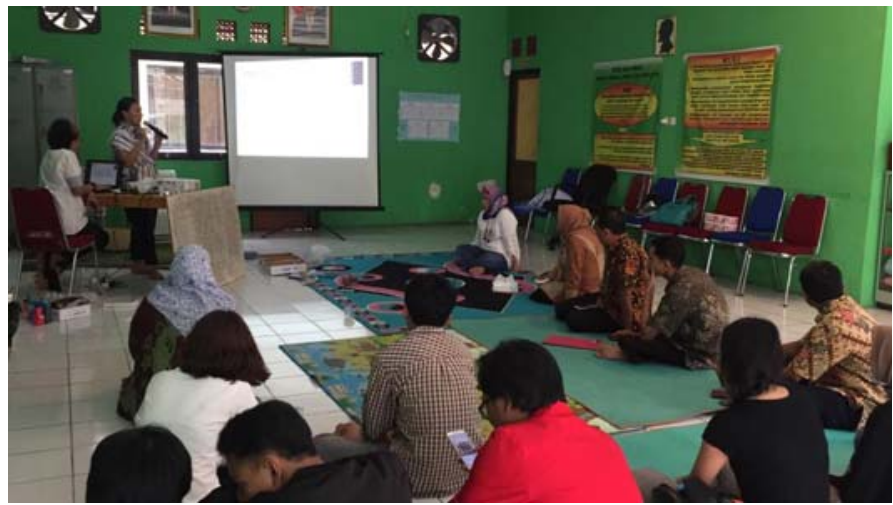

Figure 5. Training sessions with the staff and the people with disabilities 


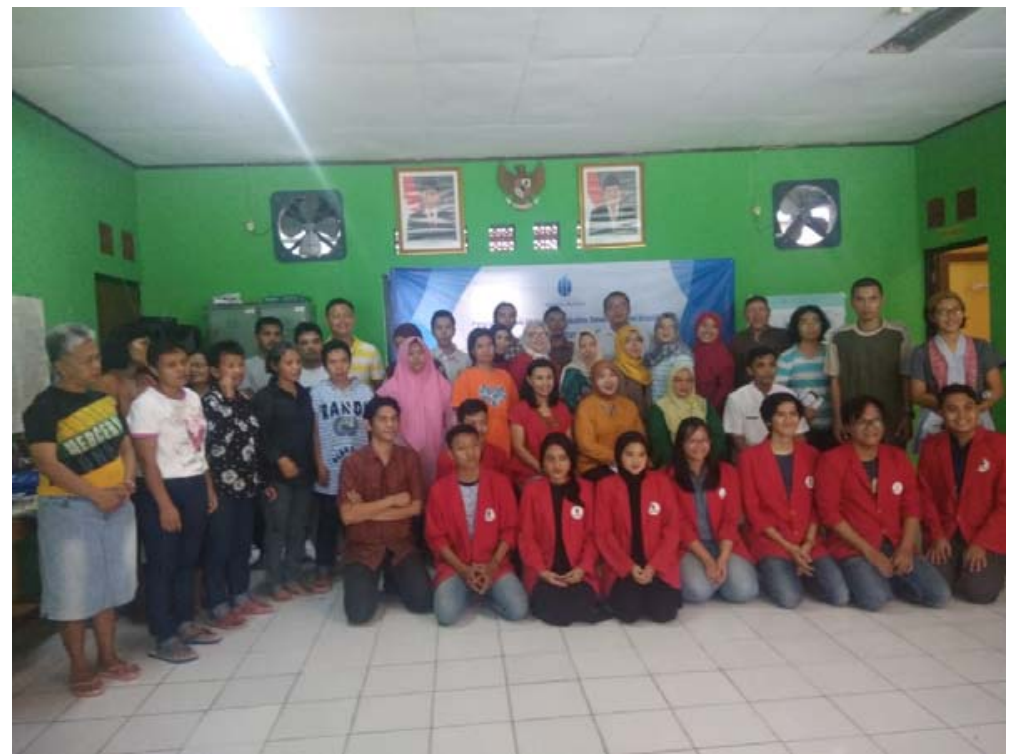

Figure 6. Photo session with the training program participants

\section{CONCLUSIONS}

Departing from the progress within the training program, several conclusions with regards to the Community Service Program from the Visual Communication Design Study Program might be drawn. These conclusions are as follows:

1. The activities in the training program have been well implemented and already in accordance to the objective of the training program.

2. The activities in the training program have been well accepted by both the members and the administrators of UILS Meruya.

3. The activities might provide new topic for the members of UILS Meruya West Jakarta in relation to the creation of media display, specifically in the context of creating interesting media that might be worth for sale.

\section{LIST OF REFERENCES}

Tjiptana. R, Gunawan. M. (2013). Visualisasi Stand Pameran Berbasis Augmented Reality dengan Menggunakan Openspaced3D. Konferensi Nasional Sistem Informasi 2013-Mataram

Tjokro, Sutanto. (2010). Presentasi Yang Mencekam. Penerbit PT Elex Media Komputindo Kompas Gramedia: Jakarta. 